\title{
A GIS-based approach for radiation risk assessment around a thermal power plant towards adopting remedial measures
}

\author{
Kajori Parial $^{1,2, *}$, S. Mukherjee ${ }^{2}$, A. R. Ghosh ${ }^{2}$ and D. Sengupta ${ }^{1}$ \\ ${ }^{1}$ Department of Geology and Geophysics, Indian Institute of Technology-Kharagpur, Kharagpur 721 302, India \\ ${ }^{2}$ Department of Science and Technology and Biotechnology, Government of West Bengal, Kolkata 700 091, India
}

\begin{abstract}
Coal combustion in thermal power plants releases ash, which is reported to cause adverse health hazards in humans and other organisms. Owing to the presence of radionuclides, it is also considered as a potential radiation hazard. In this study, based on the surface radiation measurements and relevant ancillary data, expected radiation risk zones were identified with regard to human population residing near a thermal power plant using GIS. With population density as the vulnerability determining criterion, about $20 \%$ of the study area was in the 'high' risk zone and another $20 \%$ in the 'low' risk zone. The remaining $60 \%$ was under 'medium' risk zone. Based on the findings of this study, greenbelt locations have been proposed as a remedial measure.
\end{abstract}

Keywords: Geographic information system, radiation risk analysis, remedial measures, surface radiation, thermal power plant.

COAL-BASED thermal power plants (TPPs) release different chemical substances in the environment in the form of flue gas and ash. Most of these substances, beyond a certain limit, are known to have the potential to adversely affect the environment as well as other organisms, including human beings. The continuous release of coal ash is expected to have a cumulative impact on the environment and humans in the long run. Hence, it is considered as a potential threat to the ambient environment, including the human population. The finer fraction of ash, released from the stacks, may be directly taken up by the local population, whereas the coarser bottom ash stored in ash ponds may contaminate the local soil and water resources, both surficial and underground. The major pathways for exposure to the contaminants for humans are: (i) direct inhalation of ash from the moving plume; (ii) external exposure (on skin, hair), and (iii) inhalation and ingestion from deposition on soil ${ }^{1}$. In case of contamination from ash, apart from the plume, transportation and ash-handling also expose humans to the contaminants. Another possible way of exposure to these

*For correspondence. (e-mail: kajorigis@gmail.com) elements can be through surface water and groundwater. In the absence of proper monitoring and management, the situation may worsen and expose the environment and its components to the risk of being adversely affected.

The elemental concentration of ash is dependent on the coal type and is highly variable. The environmentally significant component of ash is the inorganic fraction, inherited from coal, like the primordial radionuclides $\left({ }^{238} \mathrm{U},{ }^{232} \mathrm{Th}\right.$ and $\left.{ }^{40} \mathrm{~K}\right)$, different trace elements (TEs) and rare earth elements (REEs).

Among these, radionuclides are one of the most toxic components; their presence enhances the naturally occurring radionuclide materials (NORM) concentration in a given area. The association, concentration and partitioning behaviour of these elements play a major role in deciding the environmental impact of $\mathrm{ash}^{2}$, especially for concentration of radon, thoron and associated radiation doses ${ }^{3-5}$. Several studies regarding partitioning of radionuclides in the ash particles have reported that elements like ${ }^{238} \mathrm{U}$ (compared to ${ }^{232} \mathrm{Th}$ ) and most of the TEs are found to be enriched in the fine fly-ash particles leading to higher mobility of the species ${ }^{6,7}$. Presence of toxic elements like radionuclides, along with high mobility and long residence time of fine ash particles, make the fine ash more hazardous than bottom $\mathrm{ash}^{8}$. Consequently, the probability of these particles to be wind-borne, resulting in a wide area of impact due deposition of ash, up to a considerable distance from the TPP increases. The bottom-ash particles, rich in other elements, from the open ash mounds are also wind-blown and deposited in the vicinity. As a result, enhanced concentration of radionuclides has been observed near several coal-based TPPs $^{9-13}$. In these studies, the observed radionuclide concentration at discrete locations has been used to calculate the doses. However, any damage due to radiation depends on some other factors as well. For example, hazard due to the same dose of radiation may vary from person to person depending on the environment in which they live as well as on their age, genetic make-up, health condition, etc. ${ }^{14}$. This makes risk assessment due to radiation a complex exercise. Although considering all the variables is difficult, some of the factors may be considered along with the calculated doses to obtain a better estimate of 
risk. Towards that aim, here the population density of the study area, as a function of the land-use pattern, has been considered since the cumulative dose depends on the number of individuals receiving the dose $\mathrm{e}^{15}$. As the parameters affecting the risk intensity are highly variable, it becomes essential to not only estimate the risk once but to monitor the changes periodically.

According to the recent literature, any amount of radiation carries some risk and the risk increases directly with dose $^{14}$. Varnes ${ }^{16}$ defined natural hazards as 'the probability of occurrence within a specified period within a given area of a potentially damaging phenomenon'. Hence, in this study the increased radiation occurring near a TPP due to continuous release and deposition of ash from it is designated as the 'potentially damaging phenomenon' or the 'hazard'. The analytical methods for radionuclide estimation are both time- and cost-intensive. For a fast and effective monitoring plan, in this study the approach of integrating the radiation measurements and one of the key variables - population density, in the context of spatial distribution has been adopted. The in situ radiation measurements were integrated with the demographic information on a GIS platform. The Kolaghat Thermal Power Plant (KTPP), located in Purba Medinipur, West Bengal has been considered in this study.

A few studies in the area suggested adverse impact on the environment as well as human population, especially on children ${ }^{17,18}$. An overall risk assessment of the study area due to radiation has not been reported so far. Hence, the present study has been undertaken with the following objectives: (a) to identify potential risk zones on the basis of human exposure to radiation, and (b) to recommend some remedial as well as precautionary measures.

\section{Study area}

Geographically, Kolaghat lies 60 km WSW of Kolkata, on the right bank of River Rupnarayan. Geologically, the area is made up of quaternary alluvial deposition ${ }^{19}$. The terrain is almost flat with a gentle slope towards eastsoutheast (average elevation being 5-7 m amsl). The soil is mainly alluvial with about $60 \%$ clay content ${ }^{19}$. Apart from the Rupnarayan, the two other major water bodies in the study area are Denan-Dehati canal and Medinipur canal. The better an artificial canal, is used to pump water from the Rupnarayan and supply it to KTPP for its operation. The total installed capacity of the plant is $1260 \mathrm{MW}$. There are six units, each of $210 \mathrm{MW}$. The first unit was commissioned in 1984 (ref. 20). The remaining units were commissioned from 1986 to 1994 . About 25 sq. km of the area surrounding KTPP has been studied. The localities in the area are situated as close as within the radius of a few metres from the TPP as well as the ash ponds.

\section{Methodology}

\section{Data collection}

Surface radiation in the study area, with the TPP at the centre, was recorded using a portable low-level gamma survey meter - the microR-Surveymeter (R for Roentgen; model UR-709, Nucleonix Systems Private Limited, Hyderabad, India). The instrument provides its output in dose rate. Surface radiation measurements were conducted at 95 locations spanning across the study area. In each location three readings were recorded for $100 \mathrm{sec}$ each. The sample spacing was $400 \mathrm{~m}$ on an average in an almost grid pattern. GPS locations at each site were collected. The measurements were made in microRoentgen per hour $\left(\mu \mathrm{R} \mathrm{h}^{-1}\right)$, and were converted to nanogray per hour (nGy $\mathrm{h}^{-1}$; dose) by applying suitable conversion factor. Figure 1 shows a schematic overview of the methodology used.

\section{Preparation of maps}

The land-use map was prepared through on-screen visual interpretation technique (Figure 1) in GIS platform at a scale of $1: 22,000$ with UTM Projection, WGS 84 datum. LISS-IV image from ResourceSat 2 satellite, acquired on 17 April 2012, was used for land-use map preparation. Google Earth image was used as reference for map generation of the study area. The land-use map was verified through intensive field visits. The major land-use classes interpreted in the area were settlements with homestead orchards, agricultural lands, industrial lands, open space, river and canals, surface water bodies, road and railways. The settlement-wise population density was calculated

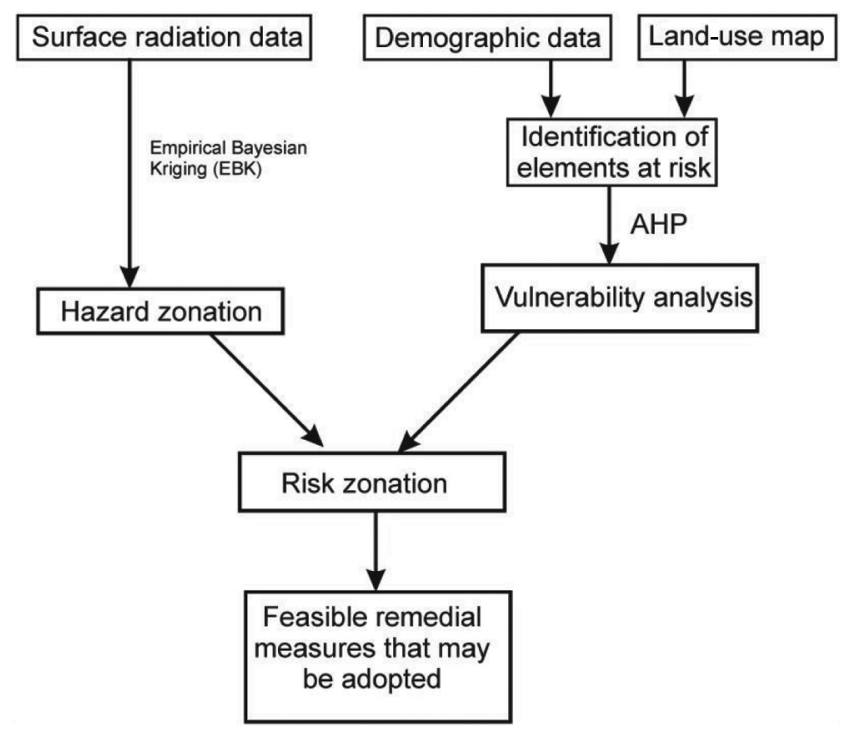

Figure 1. Schematic overview of risk analysis methodology. 
using settlement area of the respective mouzas, computed from the land-use map, and the population of each mouza as retrieved from the census data ${ }^{21}$. The hazard, vulnerability and risk analyses were performed using GIS.

Radiation hazard zonation: The zonation of the study area on the basis of surface radiation measurements was done following the recommendation of the populationweighted average absorbed dose rate (in air outdoors from terrestrial gamma hazard) of $60 \mathrm{nGy} \mathrm{h}^{-1}$ by the United Nations Scientific Committee on Environmental and Atomic Radiation, $\mathrm{USA}^{22}$. The surface radiation data collected for the study area were interpolated. Empirical Bayesian kriging (EBK) method was used to obtain a kriged layer of interpolated dose over the entire area followed by reclassification of the newly generated surface based on the population-weighted average absorbed dose rate of $60 \mathrm{nGy} \mathrm{h}^{-1}$ as the threshold value. EBK is a geostatistical interpolation technique based on the empirical Bayes estimation method ${ }^{23}$. Traditional kriging methods ignore the error introduced due to estimating the semivariogram from the known data points, assuming that it is the true semivariogram ${ }^{24}$. However, EBK by virtue of its properties, estimates the error in the semivariogram as well. This results in a better estimation of the error in the prediction $^{24}$ and hence was used in the present study. Two zones were created: low hazard zone with values $\leq 60 \mathrm{nGy} \mathrm{h}^{-1}$ and high hazard zone with values $>60 \mathrm{nGy} \mathrm{h}^{-1}$.

Vulnerability analysis: Vulnerability is a relative term and different fields have their own conceptual description of vulnerability as well as risk ${ }^{25}$. In this study, vulnerability is referred to as the extent to which human populations residing in the neighbourhood of a TPP are expected to experience the adverse impact due to radiation. The vulnerability analysis traditionally involves ranking of different 'elements at risk', followed by assignment of a score to each element on the basis of ranks. In the present study, analytical hierarchical process (AHP) was used to calculate the vulnerability scores for the determining criteria - high population density, medium population density, low population density, agriculture, waterbodies and open space.

AHP is an internationally accepted robust and flexible multicriteria decision-making tool ${ }^{26}$. The basic concept of AHP is to decompose a complex decision problem into a hierarchical structure of goal, criteria, sub-criteria and alternatives followed by pairwise comparison of the elements in terms of a ratio scale based on both qualitative and quantitative information about the elements. The ratio scale generally ranges from 1 to 9 , where 1 indicates equal importance of both the elements and 9 indicates an extremely strong significance of one element over the other ${ }^{27}$. The ratios are used to construct a comparison matrix ( say $A$ ). This matrix must be transitive, i.e. if $i, j$ and $k$ are the alternatives and if $i>j$ and $j>k$, then $i>k$; for all $i, j$ and $k$; and reciprocal $a_{i j}=1 / a_{j i}$. Each column of the comparison matrix is normalized using its principal eigenvector (or positive multiple of the vector), and $\lambda_{\max }$ is the principal eigenvalue of the matrix (eq. (1) $)^{27-31}$.

$$
A w=\lambda_{\max } w .
$$

In this study, the weightage for each criterion was generated according to Saaty's 'fundamental nine-point scale for comparative judgements ${ }^{32}$. The weightage for population density was generated considering the fact that radiation risk in terms of collective dose increases with higher population density, and vice versa ${ }^{15}$. The weightage for rivers, waterbodies and agricultural lands was generated considering the reports of adverse effect of ash on them. Since the local population generally consumes the local produce of fishes and crops in the study area, some adverse effects are expected due to their intake.

Risk analysis: Risk was calculated as a function of radiation score and vulnerability score. Based on the risk score obtained, the final risk map was generated. In the present study, three risk zones were created based on the risk score. Jenks natural break method was used to classify the area into different zones $^{33}$. The areas with risk score $<40$ were designated as low risk zone; medium risk comprised of areas with score 40-60, and areas with risk score $>60$ were designated as high risk zones.

\section{Results and discussion}

Figure 2 shows the land-use map of the study area. The percentage of area covered by the major land-use types is as follows: settlements with homestead orchards (36), agriculture (36), surface waterbodies (including canals, 7.9, industrial area (6.2) and ash ponds (2.7).

Table 1 gives the pairwise comparison between the criteria using AHP. Table 2 gives vulnerability rank for each criterion. The consistency ratio of the analysis was found to be $7.2 \%$.

Figure 3 shows the radiation zones. About 37\% of the total area is found to be 'low hazard' zone, receiving dose rate below or equal to $60 \mathrm{nGy} \mathrm{h}^{-1}$. The remaining $63 \%$ area comes under the 'high hazard' zone receiving average ambient dose rate $>60 \mathrm{nGy} \mathrm{h}^{-1}$.

The latter zone is present towards the north and the former zone is present towards the south and southeast of the study area. The high hazard zone primarily coincides with ash ponds and TPPs. The two probable reasons for such kind of distribution of surface radiation in the area as follows: (i) Airborne deposition of fine ash particles In this area, the prevalent wind direction is from south and southwest to north and northeast. As a result, loose and fine-sized ash particles from the ash ponds and stack can get easily transported towards the north, resulting in a 


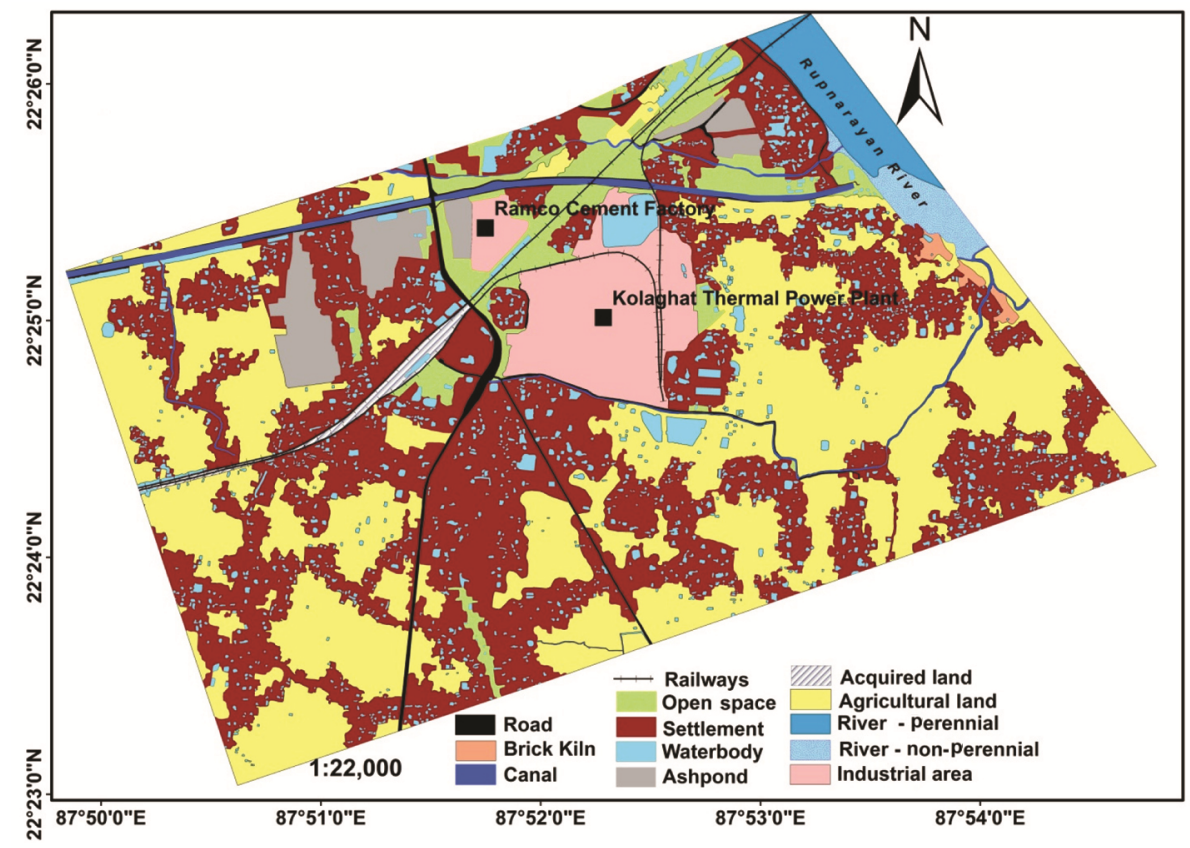

Figure 2. Land-use map of the study area.

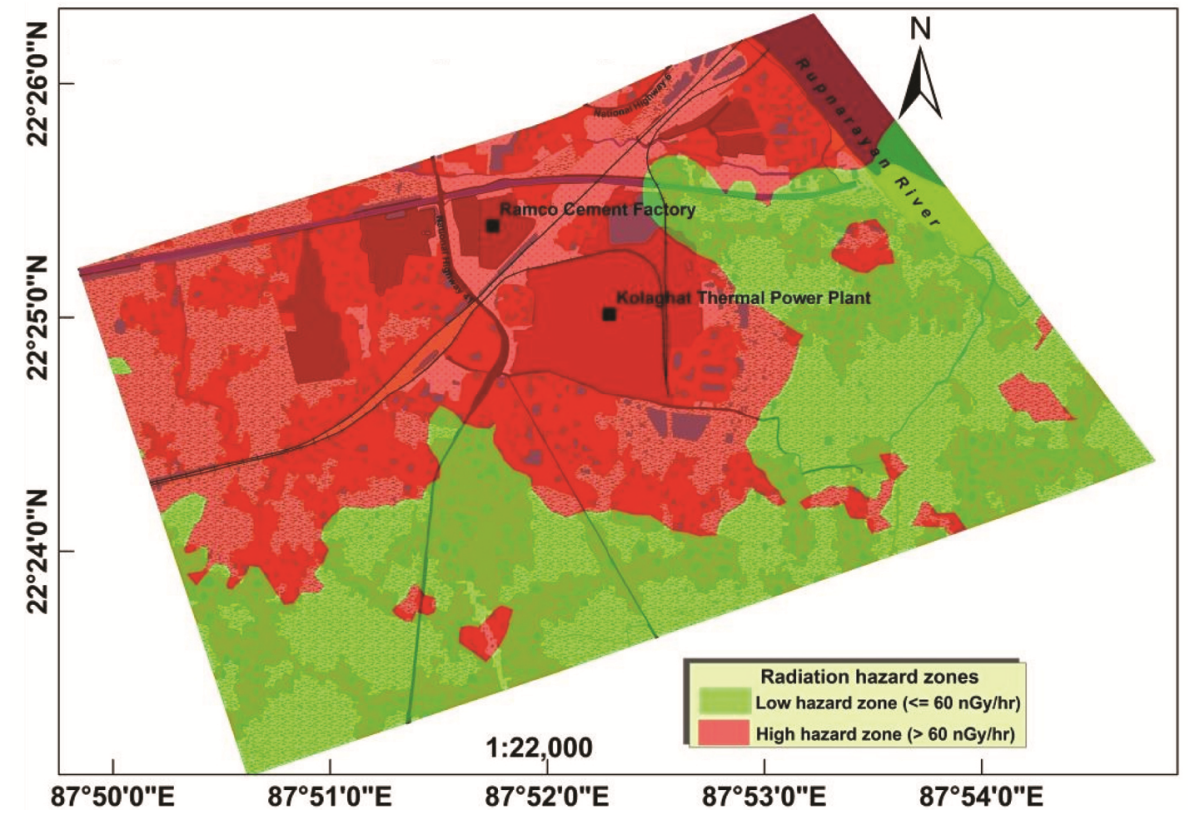

Figure 3. Radiation zone map of the study area.

high surface radiation. (iii) Use of fly ash for land filling - Huge amount of bottom ash is used to fill up lowlying areas and making embankment for railways, roads and highways in the study area. The large volume of ash involved in such applications is a significant contributor to the ambient surface radiation. Hence the northern part of the study area experiences higher surface radiation compared to the southern part. In the southern part, both ash ponds, and railway and road network are absent. Besides, it is opposite to the prevalent wind direction, and hence wind-borne deposition of the fine fly ash particles is less.

The ash ponds, industrial areas, rivers, water bodies, open spaces and agricultural lands have a lower vulnerability rank as the population density in these areas is almost negligible.

Figure 4 shows the radiation risk zones. The risk map shows that, although a large area $(63 \%)$ is estimated to be under high hazard zone, the area under high risk zone is less. About $20 \%$ of the area is under high risk. The low 


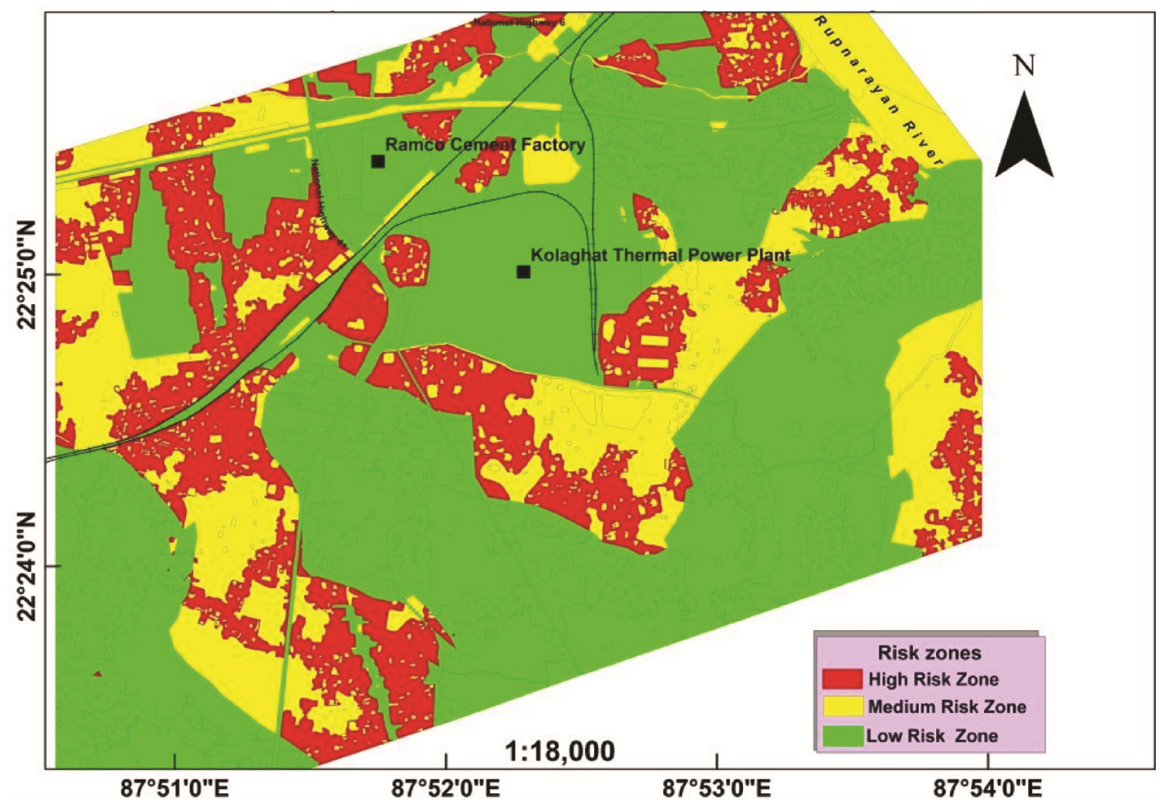

Figure 4. Radiation risk zone map of the study area.

Table 1. Pairwise comparison matrix of the criteria for Analytical Hierarchical Process

\begin{tabular}{|c|c|c|c|c|c|c|}
\hline Criteria & $\begin{array}{l}\text { High population } \\
\text { density (HPD) }\end{array}$ & $\begin{array}{l}\text { Medium population } \\
\text { density (MPD) }\end{array}$ & $\begin{array}{l}\text { Low population } \\
\text { density (LPD) }\end{array}$ & Agriculture & Waterbodies & $\begin{array}{l}\text { Open space } \\
\text { (OS) }\end{array}$ \\
\hline HPD & 1 & 3 & 5 & 6 & 6 & 8 \\
\hline MPD & 0.33 & 1 & 3 & 5 & 5 & 7 \\
\hline LPD & 0.20 & 0.33 & 1 & 4 & 5 & 8 \\
\hline Agriculture & 0.17 & 0.20 & 0.25 & 1 & 1 & 3 \\
\hline
\end{tabular}

The consistency ratio is $7.2 \%$.

Table 2. Importance of weights

\begin{tabular}{lcc}
\hline Criteria & Priority (\%) & Rank \\
\hline HPD & 44.9 & 1 \\
MPD & 25.2 & 2 \\
LPD & 16.2 & 3 \\
Agriculture & 5.5 & 4 \\
Waterbodies & 5.4 & 5 \\
Open space & 2.7 & 6 \\
\hline
\end{tabular}

risk zone also covers $20 \%$ of the study area, and rest of the area is under medium risk. Such distribution of risk is because most of the high radiation zones are devoid of any human settlement. Since the study mainly focused on the adverse impact of radiation dose on the human population, areas with no population were found to be less vulnerable.

\section{Remediation}

The present study highlights the need to adopt appropriate remedial measure(s). A feasible remediation option in this study may be the setting-up of a 'greenbelt'. The alluvial soil found in the study area can be used as a resource for the planting of trees along ash ponds. This can significantly reduce the risk due to the wind-blown ash. Figure 5 is a schematic diagram showing the pattern of plantation that may be adopted to minimize exposure to ash. Based on the land-use and risk map of the study area, two tiers of plantation can be adopted. The belt may contain both shrubs and trees (Figure 5), and may be placed around the embankments of ash ponds and close to the human settlements.

Based on the risk zones identified in this study, Figure 6 shows the probable areas where of greenbelts can be setup. However, it is to be mentioned that the actual site for plantation needs to be finalized after ensuring participatory planning involving the local population. This greenbelt is expected to significantly reduce the exposure of the local population to ash from the ash ponds as well as from stack emission.

\section{Conclusion}

The hazard map shows the distribution of hazard in the study area due to surface radiation. About $63 \%$ of the total area has dose rate above $60 \mathrm{nGy} \mathrm{h}^{-1}$, and the rest has 


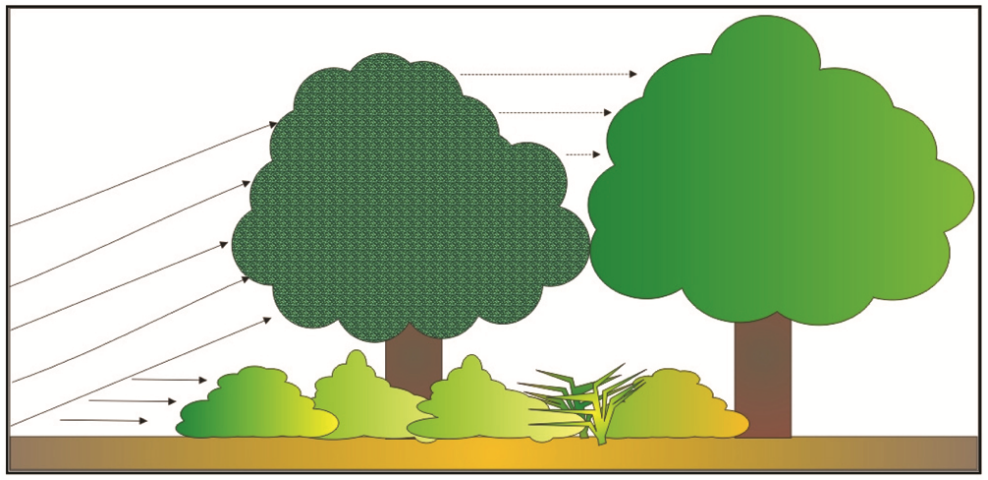

Figure 5. Schematic diagram of proposed greenbelt plantation pattern around ash ponds, Kolaghat Thermal Power Plant.

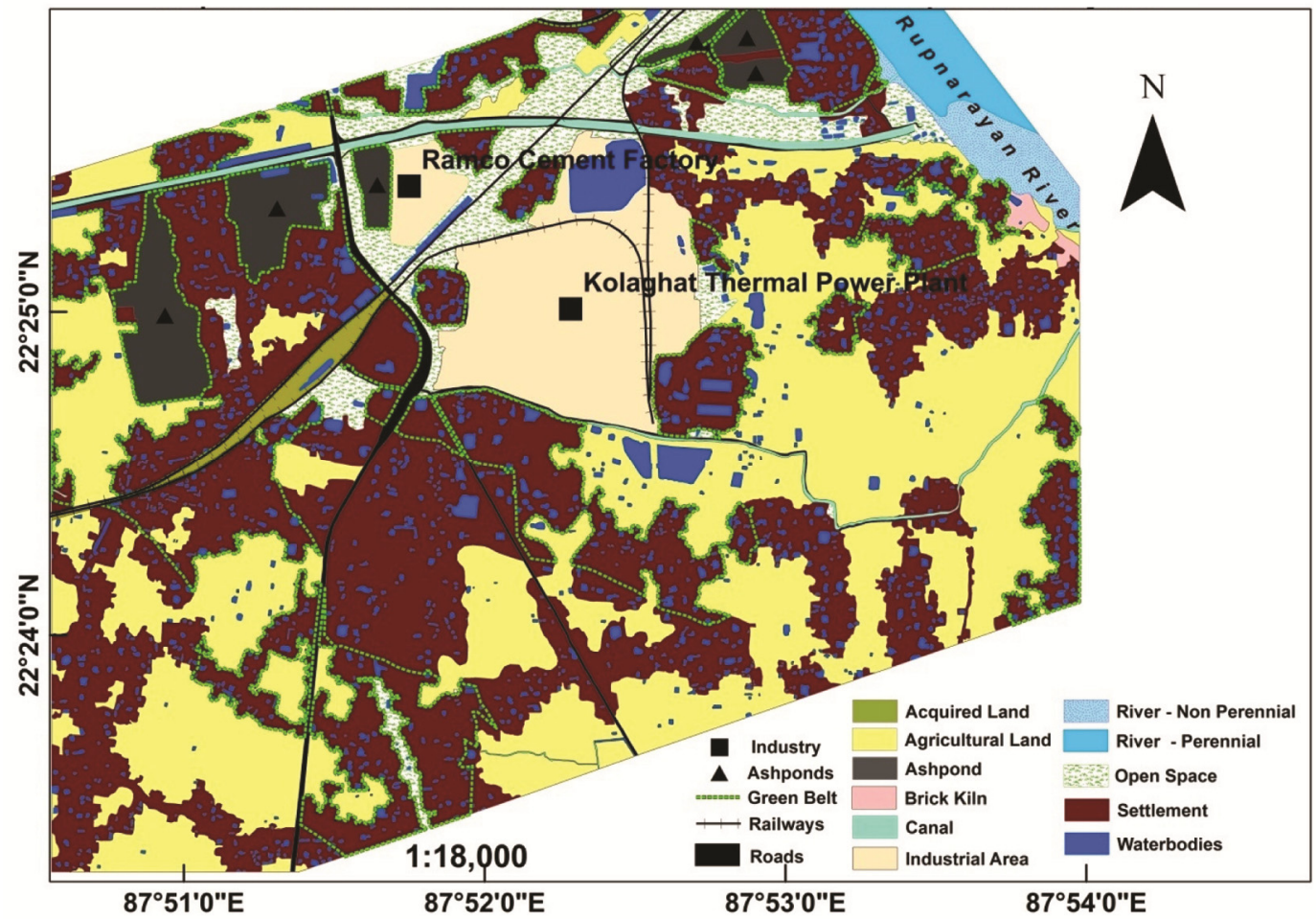

Figure 6. Proposed location of the greenbelt based on risk zone map of the study area.

dose rate below $60 \mathrm{nGy} \mathrm{h}^{-1}$. The radiation risk zonation map of the study area also shows that, since hazard and risk are not synonymous, mere identification of hazard zones can overestimate or underestimate the gravity of the situation. Hence, apart from measuring and estimating the concentration of contaminants in the environment, it is necessary to estimate the resultant risk as well.

The radiation zone map, vulnerability map and risk map generated can also be used for future planning in the study area. The radiation hazard zone map can be used to determine areas where, in future, new settlements can be established or are to be averted. For example, the high hazard zones may be strictly avoided for human occupancy in any form. In addition, these areas may be avoided for creating ash ponds in future. The highly vulnerable areas should be monitored regularly and should preferably be avoided for any further increase in hazardous activities like creation of ash ponds and ash handling. The risk map generated based on the radiation and vulnerability maps shows the distribution of radiation-induced risk in the study area. This map may play a key role in both identifying the areas demanding immediate intervention, as well as deciding upon the type of remedial measure that can be adopted. Setting up greenbelts was found to be a feasible option in this study area. The risk map may be used to identify the areas for planting trees.

1. Amin, Y. M., Khandaker, M. U., Shyen, A. K. S., Mahat, R. H., Nor, R. M. and Bradley, D. A. Radionuclide emissions from a 
coal-fired power plant. Appl. Radiat. Isot., 2013, 80, 109-116, doi:10.1016/j.apradiso.2013.06.014.

2. Nalbandian, H., Trace Element Emissions from Coal, 2012; IEA Clean Coal Centre, CCC/203, ISBN 9789290295235.

3. Sahu, S. K., Tiwari, M., Bhangare, R. C., Ajmal, P. Y. and Pandit, G. G., Partitioning behavior of natural radionuclides during combustion of coal in thermal power plants. Environ. Forensics, 2017, 18, 36-43; doi:10.1080/15275922.2016.1230910.

4. Flues, M., Camargo, I. M. C., Silva, P. S. C. and Mazzilli, B. P., Radioactivity of coal and ashes from Figueira coal power plant in Brazil. J. Radioanal. Nucl. Chem., 2006, 270, 597-602.

5. Karangelos, D. J., Petropoulos, N. P., Anagnostakis, M. J., Hinis, E. P. and Simopoulos, S. E., Radiological characteristics and investigation of the radioactive equilibrium in the ashes produced in lignite-fired power plants. J. Environ. Radioact., 2004, 77, 233 246; doi:10.1016/j.jenvrad.2004.03.009.

6. Bhangare, R. C., Ajmal, P. Y., Sahu, S. K., Pandit, G. G. and Puranik, V. D., Distribution of trace elements in coal and combustion residues from five thermal power plants in India. Int. J. Coal Geol., 2011, 86, 349-356; doi:10.1016/j.coal.2011.03.008.

7. Flues, M., Sato, I. M., Scapin, M. A., Cotrim, M. E. B. and Camargo, I. M. C., Toxic elements mobility in coal and ashes of Figueira coal power plant, Brazil. Fuel, 2013, 103, 430-436; doi:10.1016/j.fuel.2012.09.045.

8. Xu, M., Yan, R., Zheng, C., Qiao, Y., Han, J. and Sheng, C., Status of trace element emission in a coal combustion process: a review. Fuel Process. Technol., 2003, 85, 215-237; doi:10.1016/ S0378-3820(03)00174-7.

9. Lu, X., Zhao, C., Chen, C. and Liu, W., Radioactivity level of soil around Baqiao coal-fired power plant in China. Radiat. Phys. Chem., 2012, 81, 1827-1832, doi:10.1016/j.radphyschem. 2012.07.013.

10. Corbacho, J. A. and Baeza, A., Measurement of natural radionuclides and external radiation exposure due to fly ash from a coalfired power plant (Spain) deposited on soils - comparison using two different measurement techniques. Radiat. Prot. Dosim., 2018, 1-8, doi:10.1093/rpd/ncy083.

11. Lu, X., Li, L. Y., Wang, F., Wang, L. and Zhang, X., Radiological hazards of coal and ash samples collected from Xi'an coal-fired power plants of China. Environ. Earth Sci., 2012, 66, 1925-1932; doi:10.1007/s12665-011-1417-x.

12. Liu, G., Luo, Q., Ding, M. and Feng, J., Natural radionuclides in soil near a coal-fired power plant in the high background radiation area, South China. Environ. Monit. Assess., 2015, 187, 356, doi:10.1007/s10661-015-4501-y.

13. Charro, E. and Peña, V., Environmental impact of natural radionuclides from a coal-fired power plant in Spain. Radiat. Prot. Dosim., 2013, 153, 485-495; doi:10.1093/rpd/ncs 126.

14. https://www.epa.gov/radiation/radiation-health-effects

15. Tadmor, J., Radioactivity from coal-fired power plants : a review. J. Environ. Radioact., 1986, 4, 177-204.

16. Varnes, D. J., Landslide hazard zonation: a review of principles and practice. Natural Hazards, UNESCO, Paris, 1984, 3; ISBN 923-101895-7.

17. Adhya, S., Management of fly ash of Kolaghat thermal power station, Purba Medinipur, West Bengal. Electron. Int. Interdiscip. Res. J., 2014, III, 32-43.
18. Pramanik, P., Chowdhury, R., Biswas, S. and Syamal, A. K., Assault of coal-fired thermal power plant on pulmonary health of school boys aged 7 to 15 years. IOSR J. Dent. Med. Sci., 2015, 14, 133-139; doi:10.9790/0853-1463133139.

19. Mondal, M., Land people - a dynamic interaction of Purba Medinipur district, West Bengal. IOSR J. Pharm. 2012, 2, 56-61.

20. http://www.wbpdcl.co.in/component/content/article/14-sampledata-articles/90-generatingunits-kolaghat-overview.html.

21. Census, Villagewise Population data, Government of India, 2011; http://censusindia.gov.in

22. UNSCEAR, Sources and effects of ionizing radiation. United Nations Scientific Committee on Environmental and Atomic Radiation, New York, 2000.

23. Casella, G., Illustrating empirical Bayes method. Chemometr. Intell. Lab. Syst. 1992, 16, 107-125.

24. Krivoruchko, K., Empirical Bayesian Kriging, Environmental Systems Research Institute (ESRI) Press, Redlands, CA, USA, 2012, pp. 6-10.

25. Glade, T., Birkmann, J. and Fuchs, S., Vulnerability assessment in natural hazard and risk analysis: current approaches and future challenges. Nat. Hazards, 2012, 64, 1969-1975; doi:10.1007/ s11069-012-0352-9.

26. Chatzimouratidis, A. I. and Pilavachi, P. A., Objective and subjective evaluation of power plants and their non-radioactive emissions using the analytic hierarchy process. Energ. Policy, 2007, 35, 4027-4038; doi:10.1016/j.enpol.2007.02.003.

27. Saaty, T. L., Decision making - the analytic hierarchy and network processes (AHP/ANP). J. Syst. Sci. Syst. Eng., 2004, 13, 1-35.

28. Bello-Dambatta, A., Farmani, R., Javadi, A. A. and Evans, B. M., The analytical hierarchy process for contaminated land management. Adv. Eng. Inform., 2009, 23, 433-441; doi:10.1016/j.aei. 2009.06.006.

29. Bhushan, N. and Rai, K., The analytic hierarchy process. In Strategic Decision Making: Applying the Analytical Hierarchy Process, Springer-Verlag London, 2004; pp. 11-21; ISBN 1-85233-756-7.

30. Saaty, R. W., The analytic hierarchy process - what and how it is used. Math. Model., 1987, 9, 161-176.

31. Saaty, T. L., A scaling method for priorities in hierarchical structures. J. Math. Psychol., 1977, 15, 234-281.

32. Saaty, T. L., Decision making with the analytic hierarchy process. Int. J. Serv. Sci., 2008, 1, 83-98.

33. Jenks, G., The data model concept in statistical mapping. Int. Yearb. Cartogr., 1967, 7, 186-190.

ACKNOWLEDGEMENTS. K.P. thanks University Grants Commission, New Delhi for providing financial support to conduct this work. The authors also thank Indian Institute of Technology, Kharagpur, and Geoinformatics and Remote Sensing Cell, Department of Science and Technology and Biotechnology, Government of West Bengal for providing necessary support.

Received 12 July 2017; revised accepted 13 February 2019

doi: $10.18520 / \mathrm{cs} / \mathrm{v} 116 / \mathrm{i} 10 / 1683-1689$ 